\title{
A Projection Pursuit Model Optimized by Free Search: For the Regional Power Quality Evaluation
}

\author{
Yu Yun-jun ${ }^{1,2, *}$, Tong $\mathrm{Chao}^{1}$, Xue Yun-tao ${ }^{1}$, Peng Sui ${ }^{1}$, Li Yuan-hao ${ }^{1}$ and Xin Jian-bo ${ }^{2}$ \\ ${ }^{1}$ College of Information Engineering, Nanchang University, Nanchang, Jiangxi, 330031, China; ${ }^{2}$ Jiangxi Electric Power \\ Research Institute, Nanchang, Jiangxi, 330096, China
}

\begin{abstract}
A Projection Pursuit Model Optimized by Free Search is proposed for power quality comprehensive evaluation high dimensional index system. This model constructs the comprehensive evaluation function of projection pursuit, transforms the electrical energy evaluation index of diversity of unidirectional power index evaluation, avoiding the conventional evaluation methods of human subjective weighting on the result of evaluation. In order to find the best projection direction and to seek the optimal solution quickly, a free global optimization search algorithm is used, which can avoid falling into local suboptimal characteristics and to optimize the projection pursuit evaluation function effectively. After optimizing the best projection direction, which is able to reflect the various power indicators on the importance of the power quality comprehensive evaluation results. The evaluating model is proved by examples, the evaluation results of the model more and more accurate.
\end{abstract}

Keywords: Comprehensive evaluation system, free search, power quality, projection pursuit.

\section{INTRODUCTION}

With the continued attention of the power quality, more and more evaluation methods of power quality have been proposed.

In practical work, we often need to evaluate power quality of the determined region. Usually, people determine the power quality rank is based on the evaluation results of the comprehensive evaluation of power quality model, and then to make the rewards and punishment measures [1-4].

At present, the typical power quality comprehensive evaluation methods are: the probability and vector algebra method, fuzzy mathematics method, the matter element analysis method, artificial neural network method and the projection pursuit method. In Paper 7, combined with the statistical characteristics, it adopts the Probability and Statistics Feature Value Method to captures the partial electric energy quality indicators to assess the regional power quality. But in the standardize process of indices of probability distributions of expected value and standard deviation, the selection of basic value improperly will cause greater error. By using the fuzzy recognition method in paper 8 , it can avoid the evaluation error of the base value selection, but it's careful, clear and comprehensive. Paper 8 put forwards the matter element analysis method, the method makes a comprehensively evaluates on the regional power quality, and it's easy to be programmed and realized. But it needs to the assign the weight of index in the evaluation of power quality by artificial means. Paper 10 put forwards the comprehensive evaluation based on radial basis function neural network [5-9].
This method without any artificial empowerment and through the neural network training, it can reflect the inherent relationship between evaluation indexes objectively. But it needs a large number of samples in the evaluation before evaluating, which will effect the assessment speed.

In order to solve the above problems, Paper 11 put forwards the projection pursuit method, with the Genetic Algorithm (GA), Ant Colony Algorithm (ACA) and Particle Swarm Optimization (PSO), to find out the best projection direction fast by optimizing projection index function. But it appears the problem of "premature convergence", and can not always get the optimal results. Aiming at this problem, this paper proposes a regional power quality evaluation model based on free search and projection pursuit model optimization.

By constructing the projection pursuit comprehensive power quality evaluation function, the high dimensional evaluation index is projected to one dimensional, with global convergence of free search which can effectively avoid the local suboptimal characteristics to optimize the best projection direction, to achieve a comprehensive evaluation of power quality objectively. Examples prove that, the evaluation model is simple in calculation, strong applicability, and the evaluation result is more accurate and objective [10-18].

\section{A PROJECTION PURSUIT MODEL OPTIMIZED BY FREE SEARCH}

The power quality date include voltage deviation, voltage sag, three-phase unbalance, voltage fluctuation, voltage flicker, frequency deviation, the rate of total harmonic distortion, power supply reliability, service indicators etc. Data are non-normal, nonlinear, high dimension, is not conducive to comprehensive evaluation. Projection pursuit model basic 
train of thought: projecting high dimensional data to lower one, measured the possibility of exposed a certain structure by projection index function, and then find the projection value which can optimize the projection index function, analyzed the structural characteristics of high-dimensional data by using the projection value, or according to the projection value and research system between the input and output values of a scatter diagram to construct appropriate mathematical model for the simulation of the system output.

\subsection{Modeling Steps}

Seting up the No. i sample, No. $\mathrm{j}$ target as $x_{i j}$ according to the power quality data sheet of the power quality samples, $i=1,2, \cdots, n, j=1,2, \cdots, m, n$ is the number of sample, $m$ is the number of target.

Step One: Eliminate dimension: sample evaluation index standardization processing. Evaluation index generally contains different types of index of different dimensions, therefore needing to make consistent processing on indicators and eliminate dimension.

We standardizing raw data evaluation indexes by using poor law. First of all, needing to determine indicators. Then each handle, specific process is as follows:

For efficiency index $u_{i j}$, command

$x_{i j}^{*}=\left[\frac{x_{i j}-x_{j \min }}{x_{j \max }-x_{j \min }}\right]$

For the cost target $u_{i j}$, command

$x_{i j}^{*}=\left[\frac{x_{j \max }-x_{i j}}{x_{j \max }-x_{j \min }}\right]$

Among them $x_{j \max }$ and $x_{j \min }$ is the maximum and the minimum of the No. $\mathrm{j}$ the original evaluation index data; $x_{i j}^{*}$ dimensionless, and $0 \leq x_{i j}^{*} \leq 1$.

Step Two: construct the projection index function. Projection is essentially from a different Angle to observe the data, so we can looking for the best the viewing angle for reflect the characteristics of the data and the full mining data information as far as possible, that is the optimal projection direction. Putting the $m$ d power quality data Integrated into one dimension projection value of quality data $z_{i}$ which using $W=\left[w_{1}, w_{2}, \cdots, w_{m}\right]$ as the projection direction, then classified depends on the image intuitive one dimensional spread of $z_{i}$, in order to easy to use simple method for highdimensional data analysis and processing. the onedimensional projection characteristic value $z_{i}$ of $x_{i j}^{*}$, can be represented as:

$z_{i}=\sum_{j=1}^{m} w_{j} \times x_{i j}^{*},(i=1,2, \cdots, n)$

$z=\left(z_{1}, z_{2}, \cdots, z_{n}\right) \quad$ is projection eigenvalue vector, $z_{i j}=w_{j} \times x_{i j}^{*}$ is the projection weight of the No. i sample, No. j target.
Step Three: To construct the objective function, in order to the structure of the data combination characteristic from multidimensional data of power quality, we required to extract One dimension projection value $z_{i}$ from the variation informationas of the $x_{i j}^{*}$ as much as possible when the general projection, that the class spacing $S_{z}$ of $z_{i}$ should as large as possible in one dimensional space. At the same time, the local density $D_{z}$ of the one dimension projection value $z_{i}$ achieve maximum, that indicators in the same projection space focus as far as possible. Build a projection objective function:

$Q(w)=S_{z} \times D_{z}$

$S_{z}$ is the standard deviation of $z_{i}, D_{z}$ is the local density of $z_{i}$

$S_{z}=\sqrt{\frac{\sum_{i=1}^{n}\left(z_{i}-E_{z}\right)^{2}}{(n-1)}}$

$D_{z}=\sum_{i=1}^{n} \sum_{j=1}^{n}\left(R-r_{i j}\right) \times u\left(R-r_{i j}\right)$

$E_{z}$ is the average of $z_{i}, R$ is related to the characteristics of data, as the density of local density window width, selection of it not only should consider to avoid make the projection point of the average number included in the window is too little, avoid moving average deviation is too big, but also I can't make it increases with the increase of $\mathrm{n}$ too much, $R$ can generally be values for $k S_{z}$, among them $k$ can be 0.1 , 0.01 or 0.001 etc, we can properly adjust according the zero $z_{i j}$ in the regional distribution; distance $r_{i j}=\left|z_{i}-z_{k}\right|(k=1,2, \cdots, n)$ is the distance between two projection characteristic value; $u$ is the unit step function, function value is zero when $R-r_{i j} \leq 0$; function value is one when $R-r_{i j} \geq 0$.

Step Four: To optimize the projection direction, different projection direction reflect the characteristics of the different data structure, and the best projection direction is the largest possible exposure to high-dimensional data certain characteristic of the structure of the projection direction. Therefore we can estimate the best projection direction by solving the projection index function maximization

$\left\{\begin{array}{l}\operatorname{Max}: Q(w)=S_{z} \times D_{z} \\ \text { s.t.: }\left\|w_{j}\right\|=1\end{array}\right.$

This is a complicated nonlinear optimization problem as $w_{j}$ is optimization variables, it is difficult to process with conventional optimization method. This paper adopts the FS algorithm, we make each individual position vector to represent the projection direction in the process of iteration algorithm, it can simplify the optimization problem of processing.

Step Five: Determine the projection values. We put the best projection direction value $w_{j}$ into the projection index function, each sample projection value $z_{i}$ can be obtained, because the projection value is the best projection direction 
of each evaluation index and evaluation standard of weighting, we can evaluate the sample and analysis according to the size of the projection value.

\subsection{Free Search Algorithm Implementation}

In the above, we mentioned the optimizing of $w_{j}$ is a complicated nonlinear optimization problem, it is difficult to process with conventional optimization method. Free search model in the aspect of function optimization and its application has better optimization performance [14], it does not depend on initial value, which can avoid falling into local optimum effectively. Free search model is modeled after some groups in the biological behavior, such as finding food or water, from the population as a whole, In an orderly process, the individual among them also have individual behavior In harmony with the whole process. Group behavior characteristics mainly rely on intuition and exercise to reach the final purpose, which sport is on intuition guided by a concrete implementation of decision-making process, each individual can have two ways: searching in small steps near the neighborhood and scoping step of survey in the global. Optimization of the steps:

Step One: Optimizing power supply bureau power quality data. Sets the position vector of individual survey of every step to walk to the projection direction in the free search, so we can make an array:

$Y_{i}=\left[\begin{array}{c}X_{1 i} \\ X_{2 i} \\ \vdots \\ X_{m i}\end{array}\right]=\left(x_{m i j}\right)_{N \times M}=\left[\begin{array}{cccc}x_{1 i 1} & x_{1 i 2} & \cdots & x_{1 i M} \\ x_{2 i 1} & x_{2 i 2} & \cdots & x_{2 i M} \\ \vdots & \vdots & \ddots & \vdots \\ x_{N i 1} & x_{N i 2} & \cdots & x_{N i M}\end{array}\right]$

$Y_{i}$ is the No. n steps walking survey the location of the matrix of the No. $\mathrm{j}$ individual, $X_{m i}$ is the No. m steps survey the position vector when walking; $N$ is survey steps to walk, $m$ is survey step walk in the current step, $m=1,2,3, \ldots, \mathrm{N}, M$ is the search space dimension, that is the evaluation index number of samples; $j=1,2,3, \cdots, M$, $n$ is group size, that is evaluation of the sample size, $i=1,2,3, \cdots, n ; x_{m i j}$ is the $j$ dimension of the position component first $i$ individual step $m$ probe.

Adopt the strategy of random initialization

$w_{0 i j}=w_{i \min }+\left(w_{i \max }-w_{i \min }\right) \operatorname{random}_{i j}(0,1)$

$w_{i \max } w_{i \min }$ is the boundary of the search space; $\operatorname{random}_{i j}(0,1)$ is random number in $[0,1]$

Step Two: Survey of walking individuals with the following modification strategy update their location:

$$
\left\{\begin{array}{c}
x_{m i j}=x_{0 i j}-\Delta x_{m i j}+2 \Delta x_{m i j} \text { random }_{m i j}(0,1) \\
\Delta x_{m i j}=D_{i j}\left(x_{j \text { max }}-x_{j \text { min }}\right) \text { random }_{m i j}(0,1)
\end{array}\right.
$$

$x_{m i j}$ is the updated position of individual component; $D_{i j}$ is neighborhood search radius, $D_{i j} \in\left[D_{\min }, D_{\max }\right] ; \Delta x_{\text {mij }}$ is modification strategy. In fact, $D_{i j}$ plays an important role on the algorithm convergence, but for the individual has little effect on the location update. Linear decline equation pre- sented by literature [15] to determine $D_{i j}$, Because each iteration groups using the same $D_{j t}$, can be obtained

$D_{j t}=D_{\max }-C\left(D_{\max }-D_{\min }\right) / C_{\text {sum }}$

$C$ is the current algorithm iterations; $C_{\text {sum }}$ is the total number of iteration algorithm, $C=1,2,3, \cdots, C_{\text {sum }}$. This can not only has better overall search ability at the start of operation, but also has a good local search ability in the late, to obtain the global optimal solution in the survey in the walking process, Individual behavior can be expressed by:

$f_{m i}=f\left(x_{m i j}\right), f_{i}=\max \left(f_{m i}\right)$

$f\left(x_{m i j}\right)$ is the objective function of pheromone marking position value after the individual search step is completed.

The individual's pheromones:

$P_{i}=f_{i} / \max \left(f_{i}\right)$

Individual sensitivity produced:

$S_{i}=S_{\min }+\Delta S_{i}$

And the individual subject conditions:

$$
\begin{gathered}
\Delta S_{i}=\left(S_{\text {max }}-S_{\text {min }}\right) \operatorname{random}_{i}(0,1) \\
S_{\text {max }}=P_{\text {max }} \\
S_{\text {min }}=P_{\text {min }}
\end{gathered}
$$

The initial position selection and decision the next survey walking:

$x_{0 i j}^{*}=x_{i j}\left(S_{i} \leq P_{q}, \quad q=1,2,3, \cdots, M\right)$

Due to the sensitive exists randomness, the next survey results of individual choice of walking is not necessarily the best results in step $N$, This algorithm outputs the last iteration results are not necessarily the best results in the searching process, Therefore, we need to add a record comparison process, record history optimization trajectory, check the result of the last iteration algorithm. After the end of each iteration, the optimal results are compared with the group before, if the current results than before the results, will be the current result set to optimal results, through several iterations to obtain the optimal solution.

Step Three: the criterion of algorithm ending

1. The objective function to achieve the global optimal solution of the current function, that is when $f_{\max } \geq f_{\text {opt }}$ determined the end;

2. Search algebra $g$ achieve termination generation $G$; that is when $g \geq G$ determined the end;

3. The above two criteria be fulfilled a can determine the end Where $f_{\text {opt }}$ is the convergence precision value, $G$ is the maximum generation.

\section{THE ESTABLISHMENT OF COMPREHENSIVE EVALUATION SYSTEM}

According to projection of the characteristic values in the reference [11] and the formula (3) power quality comprehensive evaluation equation will be listed as follows: 


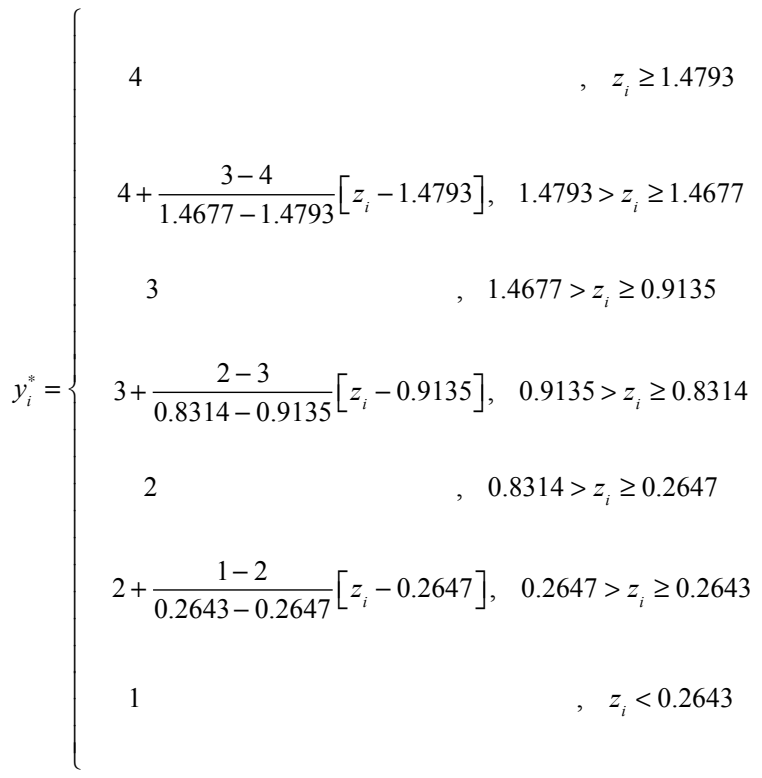

Scatter chart of rate evaluation is given in Fig. (1).

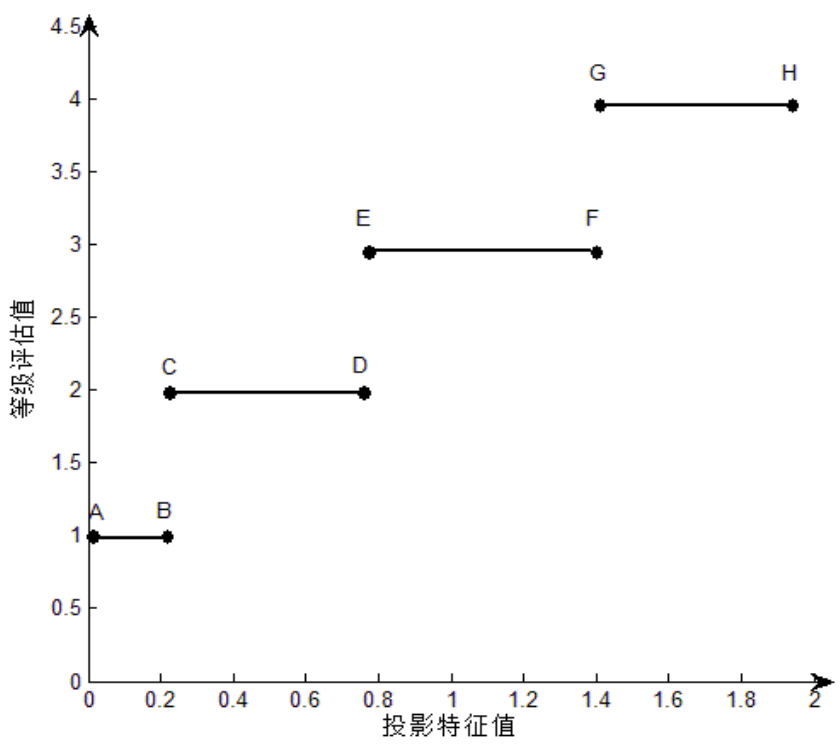

Fig. (1). Scatter diagram of optimal projection value and versus empirical grade.

\section{INSTANCE ANALYSIS}

Power quality rating threshold and data measured in various monitoring points combined with multi literatures power quality grading. The power quality will be divided into five grades: high-quality power quality, good, moderate, qualified, and unqualified. Based on the above model, the algorithm of analysis will be done according to data measured in five observation points of Power Supply Bureau given in the literature [17] power quality measurement data were numerical example. Power quality measurement data in the five observation points are shown in Table 1.

Firstly, the data samples in indicators processing equation (1) and (2) are pretreated by the way of dimensionless, the power quality monitoring data is distributed uniformly between 0 and 1 . These standard samples data are illustrated as follows:

$$
x^{*}=\left[\begin{array}{lllllllll}
0 & 1 & 0 & 0 & 0 & 0 & 0 & 1 & 0.822 \\
1 & 0 & 0.53 & 0.323 & 1 & 0.898 & 0.66 & 0.237 & 0.161 \\
0.328 & 0.56 & 0.52 & 1 & 0.43 & 0.333 & 0.266 & 0.602 & 1 \\
0.611 & 0.669 & 0.91 & 0.065 & 0.944 & 0.575 & 0.892 & 0 & 0 \\
0.291 & 0.514 & 1 & 0.403 & 0.949 & 1 & 1 & 0.258 & 0.55
\end{array}\right]
$$

The energy index data are inputted respectively into equation (3), (5), (6) and (4), resulting in the projection index function. Problems identified in equation (7) can be optimized by the freedom Search algorithm, the best projection direction can be achieved

$$
\begin{aligned}
& w=\left(\begin{array}{lllll}
0.2611 & 0.0647 & 0.5573 & 0.5455 \\
0.4168 & 0.0965 & 0.3089 & 0.0358 & 0.1994
\end{array}\right)
\end{aligned}
$$

After $\mathrm{Wj}$, optimum values, are substituted into the projector index function, each sample projected value can be obtained. In accordance with formula (17), each observation point of the power quality level values will be obtained (shown in Table 2).

The assessment results in this paper and assessment results given in reference [17] and [18] are shown in Table 3 to show the differences.

The rates given in this paper are basically same to rates given in reference [17] and [18], indicating that this model is

\begin{tabular}{|c|c|c|c|c|c|c|c|c|c|}
\hline $\begin{array}{l}\text { Observation } \\
\text { Points }\end{array}$ & $\begin{array}{c}\text { Voltage } \\
\text { Deviation / } \\
(\%)\end{array}$ & $\begin{array}{c}\text { Voltage Sags } \\
/(\%)\end{array}$ & $\begin{array}{c}\text { Three Phase } \\
\text { Unbalance / } \\
(\%)\end{array}$ & $\begin{array}{c}\text { Voltage } \\
\text { Fluctuation / } \\
(\%)\end{array}$ & \begin{tabular}{|c|} 
Voltage \\
Flicker / $(\%)$
\end{tabular} & $\begin{array}{c}\text { Total } \\
\text { Harmonic } \\
\text { Distortion } \\
\text { Rate / (\%) }\end{array}$ & $\begin{array}{l}\text { Frequency } \\
\text { Deviation }\end{array}$ & $\begin{array}{c}\text { The Power } \\
\text { Supply } \\
\text { Reliability } \\
\text { Index }\end{array}$ & $\begin{array}{c}\text { Service } \\
\text { Index }\end{array}$ \\
\hline 1 & 3.212 & 0.7963 & 0.83 & 1.33 & 0.473 & 1.72 & 0.0922 & 0.833 & 0.832 \\
\hline 2 & 6.68 & 0.1589 & 1.36 & 1.53 & 0.847 & 4.28 & 0.1562 & 0.762 & 0.713 \\
\hline 3 & 4.35 & 0.5156 & 1.35 & 1.95 & 0.634 & 2.67 & 0.118 & 0.796 & 0.864 \\
\hline 4 & 5.33 & 0.5856 & 1.74 & 1.37 & 0.826 & 3.36 & 0.1787 & 0.74 & 0.684 \\
\hline 5 & 4.22 & 0.4863 & 1.83 & 1.58 & 0.828 & 4.57 & 0.1892 & 0.764 & 0.783 \\
\hline
\end{tabular}
feasible for assessing power quality and evaluating the re-

Table 1. Practical values of index at the observation station. 
Table 2. Results of power quality evaluation based on FSPPE.

\begin{tabular}{|c|c|c|c|c|c|}
\hline Observation Points & $\mathbf{1}$ & $\mathbf{2}$ & $\mathbf{3}$ & $\mathbf{4}$ \\
\hline \hline The best projection value & 0.265 & 1.48 & 1.472 & 1.468 & 1.807 \\
\hline The rank value & 2 & 4 & 3.371 & 3.026 & 4 \\
\hline
\end{tabular}

Table 3. The evaluation results of different methods.

\begin{tabular}{|c|c|c|c|c|c|}
\hline Evaluation Method & $\begin{array}{c}\text { The Observation } \\
\text { Point 1 }\end{array}$ & $\begin{array}{c}\text { The Observation } \\
\text { Point 1 }\end{array}$ & $\begin{array}{c}\text { The Observation } \\
\text { Point 1 }\end{array}$ & $\begin{array}{c}\text { The Observation } \\
\text { Point 1 level 3 }\end{array}$ & $\begin{array}{c}\text { The Observation } \\
\text { Point 1 }\end{array}$ \\
\hline \hline The literature [17] & Level 2 & Level 4 3 & Level 4 4 \\
\hline The literature [18] & Level 2 & Level 4 & level 3 & Level 4 \\
\hline This paper & Level 2 & Level 4 & Level 3.371 376 & Level 4 \\
\hline
\end{tabular}

sults. However, the rates in this paper are 3. 731 and the rates in reference [17] and [18] are 3 in observation point 3. In observation point 4 , the rates in this paper are 3.026 , the rates in [17] are 3, and the rates in [18] are 4. The results of the assessment in this paper are more objective and reasonable.

\section{SUMMARY}

1) This paper presents a free search algorithm of projection pursuit of regional power quality evaluation model, it can make the evaluation index which reflects the quality of electric energy projected to one-dimensional by using projection pursuit algorithm, and it will make the regional power quality evaluation easier.

2) The use of free search algorithm for global optimization projection pursuit model, can quickly find the optimal projection direction, improve the classification ability of regional power quality, makes the evaluation results more objective and fair.

\section{CONFLICT OF INTEREST}

The authors confirm that this article content has no conflict of interest.

\section{ACKNOWLEDGEMENTS}

This work was financially supported by the National International Science and Technology Cooperation Project, China (2014DFG72240); National Science and Technology Support Program, China (2013BAA01B01); Natural Science Foundation of Jiangxi, China (20151BAB206051); Science and Technology Support Program of Jiangxi Province, China (2013BBE50105) and Nanchang University Create Project (20140403038, 2014147).

\section{REFERENCES}

[1] M. Zhang, T. Lin, J. Cao, and L. Liu, "Application of ideal interval method in power quality synthetic evaluation, "Power System Technology, vol. 33, no. 3, pp. 33-38, 2009.

[2] X. Zhao, C. Zhao, X. Jia, and G. Li, "Fuzzy synthetic evaluation of power quality based on changeable weight, " Power System Technology, vol. 29, no. 6, pp. 11-16, 2005.

[3] N. N. Li, Z. Y, He, "Power quality comprehensive evaluation combining subjective weight with objective weight, "Power System Technology, vol. 33, no. 6, pp. 55-61, 2009.

[4] Z. Y. Jia, and L. Zhao, "Comprehensive evaluation of power quality based on the model of entropy weight and unascertained measure, " Power System Protection and Control, vol. 38, no. 15, pp. 33-37, 2010.

[5] S. W. Kang, J. C. Peng, and Y. Q. He, "Comprehensive evaluation of power quality based on the integration of fuzzy analytic hierarchy process with multi-objective decision-making, " Power System Technology, vol. 33, no. 19, pp. 113-118, 2009.

[6] Z. J. Ding, Y. Q. Zhu, and S, Tao, “A comprehensive assessment of event-based power quality, " Power System Technology, vol. 35, no. 2, pp. 84-87, 2011.

[7] Y. W. Xiong, W. H. Cheng, and H. Q. Wang, "Synthetic evaluation of power quality based on improved AHP and probability statistics, "Power System Protection and Control, vol. 37, no. 13, pp. 48-52, 2009.

[8] S. A. Farghal, M. S. Kandil, and A. Elmitwally, "Quantifying Electric Power Quality via Fuzzy Modeling and Analytic Hierarchy Processing, "IEE Proceedings-Gener, Trans and Distrib, vol. 149, no. 1, pp. 44-49, 2002.

[9] F. Xia, L. Fan, and H. Y. Su, "A synthetic power quality evaluation model based on cloud matter element analysis theory, "Power System Protection and Control, vol. 40, no. 41, pp. 6-10, 2012.

[10] L. Zhou, Q. H. Li, H. Y. Liu, and F. Zhang, "Evaluation of power quality by fuzzy artificial neural network, "High Voltage Engineering, vol. 33, no. 9, pp. 66-69, 2007.

[11] L. Zhou, Q. H. Li, and F. Zhang, "Application of genetic Projection pursuit interpolation model on power quality synthetic evaluation, " Power System Technology, vol. 31, no. 7, pp. 32-35, 2007.

[12] Y. Y. Liu, P. Dai, and Y. H. Xu, "ComParison of Power quality comprehensive evaluation methods, "Electric Power Automation Equipment, vol. 28, no. 12, pp. 93-100, 2008.

[13] P. Kalin, and L. Guy, "Free search-a comparative analysis, " Information Science, vol. 172, pp. 173-193, 2005. 
[14] H. Zhou, D. M. Li, S. H. Shao, S. H. Shao, and C. Xu, "A novel intelligent estimation algorithm in WSN location based on freesearch, " In: IEEE International Conference on WiCOM. China, Shanghai, pp. 2629-2632, 2007.

[15] B. Wang, Z. Y. Zhang, G. H. Zhang, "Free search:A novel algorithm for optimizing irrigation schedule, "Advances Inwaterscience, vol. 19, no. 5, pp. 736-741, 2008.
[16] M. Liang, "Power quality indexes, comprehensive assessment , monitoring and management systems," Guangzhou: South China University Of Technology, pp. 1-73, 2010.

[17] H. Z. Tang, and J. C. Peng, "Research on synthetic and quantificated appraisal index of power quality based on fuzzy theory," Power System Technology, vol. 27, no. 12, pp. 85-88, 2003.

[18] X. Zhao, C. Y. Zhao, X. F. Jia, and G. Li, "Fuzzy synthetic evaluation of power qualitybased on changeable weight, " Power System Technology, vol. 29, no. 6, pp. 11-16, 2005.

(C) Yun-jun et al.; Licensee Bentham Open.

This is an open access article licensed under the terms of the Creative Commons Attribution Non-Commercial License (http://creativecommons. org/licenses/by-nc/3.0/) which permits unrestricted, non-commercial use, distribution and reproduction in any medium, provided the work is properly cited. 